\title{
Defense Mechanisms in Patients with Irritable Bowel Syndrome and Their Relationship with Symptom Severity and Quality of Life
}

\author{
Fahimeh Saeed ${ }^{1}$, Mansour Salehi ${ }^{2}$, Kaveh Alavi ${ }^{3, *}$, Hossein Ajdarkosh ${ }^{4}$,
} Fatemeh Kashaninasab ${ }^{5}$, Farnaz Nasr Esfahani ${ }^{6}$

1. Psychiatrist, Mental Health Research Center, Psychiatric Department, Iran University of Medical Sciences, Assisstant Professor of Psychiatry, Psychiatric Department, Psychosis Research Center, University of Social Welfare and Rehabilitation Sciences, Tehran, Iran

2. Associate Professor of Psychiatry, Mental Health Research Center, Psychiatric Department, Iran University of Medical Sciences, Tehran, Iran

3. Assistant Professor of Psychiatry, Mental Health Research Center, Psychiatric Department, Iran University of Medical Sciences, Tehran, Iran

4. Associate Professor of Gastroenterology, Gastrointestinal and Liver Diseases Research Center, Iran University of Medical Sciences, Tehran, Iran

5. Assistant Professor of Psychiatry, Rasoul Akram Hospital, Psychiatric Department, Iran University of Medical Sciences, Tehran, Iran

6. Psychiatrist, Mental Health Research Center, Psychiatric Department, Iran University of Medical Sciences, Tehran, Iran

\footnotetext{
* Corresponding Author:

Kaveh Alavi, MD

Mental Health Research Center, $1^{\text {st }}$ Floor, Tehran Psychiatric Institute, No 2, Shahid Mansouri St., Niayesh St., Satarkhan St., Tehran, Iran

Telefax: + 982166509025

Email: kavehalavi@yahoo.com
}

Received: 28. Dec. 2018

Accepted: 01 Jun. 2019

\section{ABSTRACT}

\section{BACKGROUND}

Despite the fact that there is theoretical evidence about the association between unconscious defense mechanisms and irritable bowel syndrome (IBS), experimental evidence in this regard is limited. The aim of the present study was to compare the defense mechanisms used by the patients with IBS and a control group, and to investigate the relationship between these mechanisms with the severity of the disease and patients' quality of life.

\section{METHODS}

Fourty-five patients with IBS (mean age of 37.1 years; 14 males) and 45 controls (mean age of 38.0 years; 13 males) were evaluated. IBS diagnosis was determined based on Rome III criteria and the predominant pattern of the disease was determined based on the patient's history (13 diarrheapredominant, 16 constipation-predominant, and 16 alternating IBS). Defense Style Questionnaire-40, IBS Severity Scale, and IBS-Quality of Life questionnaire were used.

\section{RESULTS}

The mean scores of projection, acting-out, somatization, autistic fantasy, passive-aggression, and reaction formation in the IBS group were significantly higher than the control group and the mean scores of humor and anticipation mechanisms were higher in the control group. There was no significant correlation between the score of defense mechanisms and the severity of IBS and the patients' quality of life.

\section{CONCLUSION}

The severity of immature defenses in the IBS group was significantly higher, whereas the severity of mature defenses was higher in the control group. These defenses were not correlated with the severity of IBS. Considering the limited sample size, these relationships need to be more investigated.

\section{KEYWORDS:}

Irritable bowel syndrome, Defense mechanisms, Quality of life, Functional gastrointestinal disorder

Please cite this paper as:

Saeed F, Salehi M, Alavi K, Ajdarkosh H, Kashaninasab F, Nasr Esfahani F. Defense Mechanisms in Patients with Irritable Bowel Syndrome and Their Relationship with Symptom Severity and Quality of Life. Middle East J Dig Dis 2019;11:158-165. doi: 10.15171/mejdd.2019.143.

\section{INTRODUCTION}

Irritable bowel syndrome (IBS) is one of the most common functional gastrointestinal disorders, which affects about $10-20 \%$ of the population in the Western countries and about $5-10 \%$ of the population in Asia. ${ }^{1-3}$ Although the etiology of the disease is not fully known, several hypotheses have been purposed. For example, there are recognized associations between IBS development and 
psychosocial factors, especially anxiety and stress, or traumatic events such as psychological trauma or abuse, particularly before the age of $18 .^{2,4-6}$ In this syndrome, some changes in the central amplification of pain, emotional excitement, cognitive flexibility, and endogenous inhibition of pain have been reported, which are sometimes independent of the severity of anxiety or depression..$^{5,7-9}$

Up to $80 \%$ of patients with IBS have psychiatric comorbidities, especially depression and anxiety disorders, somatization, and substance use disorders, which affect the treatment-seeking behaviors of the patients. ${ }^{10-11}$ In addition, antidepressants and a variety of psychological interventions, such as mindfulness, and analytical and interpersonal psychotherapy play an important role in the treatment of the disease. ${ }^{11-13}$

Furthermore, there is a relationship between the desire to control or suppress anger with abdominal pain and exacerbated colon movements after eating. ${ }^{14}$ Also, there is a significant relationship between anger and immature defense mechanisms in various types of functional gastrointestinal disorders, including IBS. ${ }^{15}$ It should be noted that the defense mechanisms, as defined by the fifth edition of the Diagnostic and Statistical Manual of Mental Disorders (DSM-5), are factors that mediate the responses of individuals to emotional conflicts and external stressors. ${ }^{16}$ These mechanisms are divided into three groups: Mature defenses are used by normal people to cope with various stressors and considered normal, unless excessive. Neurotic defenses are common in healthy population, however may be correlated with some psychiatric disorders, especially anxiety disorders. Immature defenses are not frequently used by healthy adults and may cause psychic disturbances and are correlated with personality disorders and other psychiatric conditions. ${ }^{17}$

Despite this theoretical knowledge, there have been only limited studies that have assessed defense mechanisms in patients with IBS. A limited study showed that in fighting against tensions, patients with IBS had more escape-avoidance and turning-against-self mechanisms than the control group. ${ }^{18}$ However, in another study, there was no significant difference in the use of the defense mechanisms between the patients with IBS and the control group. ${ }^{19}$ Yet, the relationship between these mechanisms and the types of clinical features or its severity has not been studied.
The purpose of the present study was to compare the defense mechanisms used by patients with IBS and the control group and also to investigate the relationship between these mechanisms and the severity of the disease and the patients' quality of life.

\section{MATERIALS AND METHODS}

\section{Study Design and Participants:}

This study was designed as a case-control study. The participants in this research were 45 patients with IBS and 45 controls who were selected by available sampling method. The sample size in each group was determined for an effect size of 0.6 or greater, considering $\alpha=0.5$ and $\beta=0.2$. In the patients group, the diagnosis of the disease was confirmed by a board-certified gastroenterologist, based on the Rome III criteria. ${ }^{20}$ The exclusion of other gastrointestinal disorders was based on the patient's history, physical examination, and endoscopic investigations. The predominant pattern of the disease was recorded based on the history of the patient. During the years of 2015 and 2016, these patients were referred to the gastroenterology clinic of Firouzgar Hospital.

The participants in the control group were selected from the people who accompanied the patients admitted to the gastroenterology clinic of this hospital. These participants had no major gastrointestinal diseases or acute internal illness and were sexually compatible with the patients group.

\section{Other inclusion criteria were:}

providing an informed consent for participating in the study, being literate to the extent that the individual was able to answer the questionnaires by themselves, having the physical ability to complete the questionnaires and to participate in the diagnostic interviews, and the ages of 18-64 years. Moreover, based on the semistructured clinical diagnostic interview based on DSM-IV criteria by a well-educated resident of psychiatry, ${ }^{21}$ major psychiatric disorders including schizophrenia, schizophreniform disorder, schizoaffective disorder, bipolar disorder type I, and acute mania or major depressive episodes, or substance intoxication were excluded and other psychiatric diagnoses were established. In addition, the participants who did not complete their questionnaires were excluded.

After explaining the purpose of the study and obtaining 
the written informed consents, a semi-structured clinical interview for DSM-IV was done. If necessary, supplementary questions were tailored to meet the new criteria of DSM-5. The questionnaires were then given to the participants. They were supposed to complete the questionnaires in the same place. If some questions were not answered, the participants were asked to complete the questionnaire. The study protocol was approved by the Ethics Committee of Iran University of Medical Sciences.

\section{Tools:}

Defense Style Questionnaire-40 (DSQ-40): This questionnaire was developed by Andrews and colleagues in 1993. It consists of 40 items with a 9-degree Likert scale and defines the defense mechanism based on the mature, immature, and neurotic defensive styles. ${ }^{22}$ Cronbach's alpha coefficients are satisfactory for all types of the defensive styles. ${ }^{23}$ The Cronbach's alpha coefficient of the questions of each mature, immature, and neurotic style of the Persian version in a student sample were $0.75,0.73$, and 0.74 , respectively, and its retest reliability coefficient was 0.82 with a 4 -week interval. $^{24}$

IBS Severity Scale (IBS-SS): This scale includes five questions about the number of the days with abdominal pain, pain intensity, abdominal distension, overall satisfaction with gastrointestinal function and the effect of the symptoms on everyday life. The scoring is based on a $100-\mathrm{mm}$ visual analogue scale (VAS) and its psychometric properties, including content validity, repeatability, and sensitivity to change have been desirable in numerous studies. $^{25,26}$

IBS Quality of Life Questionnaire (IBS-QOL): This questionnaire includes 34 questions with a 5-degree Likert scale and eight subscales, which measures the quality of life and was developed by Patrick and colleagues in 1998. ${ }^{27}$ The Cronbach's alpha coefficient in the original version of the questionnaire was 0.95 and in the Persian version was 0.91-0.95. Its validity was shown by correlating the scores with a variety of disease severity and quality of life scales..$^{28,29}$

\section{Statistical Analysis:}

The data were analyzed using SPSS software version 22. To compare the outcome variables between the two groups, we used Chi-square test (or Fisher's exact test, as indicated) for the qualitative variables and the independent $t$ test for the quantitative ones. The comparison of the three subgroups of IBS was done using the analysis of variance (ANOVA). The ANOVA was repeated with regard to the occurrence of the somatoform disorders and the obsessive-compulsive disorder as the probable confounders. The correlation between the variables was also calculated using Pearson's correlation coefficient. Statistical significance was assumed at the level of $p<0.05$.

\section{RESULTS}

The mean ages (years, \pm SD) in the IBS and the control groups were $37.1 \pm 11.9$ and $38.0 \pm 10.8$ years, respectively $(\mathrm{t}=0.372, p=0.711)$. There were 14 males $(31.1 \%)$ in the IBS group and 13 males $(28.9 \%)$ in the control group $\left(\mathrm{X}^{2}=0.53, p=0.818\right)$. The frequency of the people with a degree lower than diploma, diploma, and a university academic background in the IBS group was $4(8 / 9 \%), 8(18.7 \%)$, and $33(73.3 \%)$, respectively. In the control group, however, the order was $1(2.2 \%)$, $9(20.0 \%)$, and $35(77.8 \%)\left(\mathrm{X}^{2}=1.918, p=0.382\right)$. Moreover, in the IBS group, there were 2 unemployed (4.4\%), 11 housewives (24.4\%), and 32 employed $(71.1 \%)$ participants. This frequencies for the control group were in the order of the followings: $1(2.2 \%), 5$ $(11.1 \%)$, and $38(84.4 \%)\left(\mathrm{X}^{2}=3.087, p=0.214\right)$.

In the IBS group, $13(28.9 \%)$ participants had diarrheapredominant, 16 (35.6\%) had constipation-predominant, and $16(35.6 \%)$ had an alternating IBS. Among the different types of psychiatric comorbidities, the frequency of obsessive-compulsive disorder in the IBS group was significantly higher than the control group (table 1).

\section{Severity of IBS Symptoms}

39 patients with IBS $(86.7 \%)$ suffered from abdominal pain when completing the questionnaires and 42 (93.3\%) had abdominal bloating. The average number of the days that the person had a pain in the month $( \pm \mathrm{SD})$ was $4.7 \pm 2.7$. The mean pain intensity in these subjects was $49.2 \pm 22.0 \mathrm{~mm}$, the mean abdominal distension was $62.3 \pm 19.7 \mathrm{~mm}$, the mean discomfort of bowel habits was $60.5 \pm 24.4 \mathrm{~mm}$, and the mean amount of IBS interference with daily life was $52 \pm 0.29 \mathrm{~mm}$. In this way, the mean severity of the IBS (sum of the four mentioned 
Table 1: Frequency of psychiatric comorbidities among participants in the study

\begin{tabular}{|c|c|c|c|c|c|c|c|}
\hline \multirow{2}{*}{ Variables } & & \multicolumn{2}{|c|}{ IBS group } & \multicolumn{2}{|c|}{ Control group } & \multicolumn{2}{|c|}{ Chi square test } \\
\hline & & Frequency & Percentage & Frequency & Percentage & $\mathbf{X}^{2}$ & $p$ \\
\hline \multirow{4}{*}{$\begin{array}{l}\text { Somatoform } \\
\text { disorders }\end{array}$} & Illness Anxiety disorder & 5 & 11.1 & 5 & 11.1 & - & - \\
\hline & Conversion disorder & 4 & 8.9 & 1 & 2.2 & 1.096 & $* 0.361$ \\
\hline & Somatoform disorder & 11 & 24.4 & 6 & 13.3 & 1.813 & 0.178 \\
\hline & $\begin{array}{l}\text { Body dysmorphic } \\
\text { disorder }\end{array}$ & 1 & 2.2 & - & - & 1.011 & $* 1.000$ \\
\hline \multirow[t]{4}{*}{$\begin{array}{l}\text { Mood / Adjustment } \\
\text { disorders }\end{array}$} & $\begin{array}{l}\text { Major depressive } \\
\text { disorder }\end{array}$ & 12 & 26.7 & 8 & 17.8 & 1.029 & 0.31 \\
\hline & $\begin{array}{l}\text { Other depressive } \\
\text { disorders }\end{array}$ & 1 & 2.2 & - & - & 1.011 & $* 1.000$ \\
\hline & Bipolar disorder type II & 1 & 2.2 & - & - & 1.011 & $* 1.000$ \\
\hline & Adjustment disorder & 1 & 2.2 & 2 & 4.4 & 0.345 & $* 1.000$ \\
\hline \multirow[t]{6}{*}{$\begin{array}{l}\text { Obsessive / Anxiety } \\
\text { disorders }\end{array}$} & $\begin{array}{l}\text { Obsessive-compulsive } \\
\text { disorder }\end{array}$ & 15 & 33.3 & 5 & 11.1 & 6.425 & 0.011 \\
\hline & Specific phobia & - & - & 5 & 11.1 & 5.294 & $* 0.056$ \\
\hline & $\begin{array}{l}\text { Social phobia / } \\
\text { Performance anxiety }\end{array}$ & 3 & 6.7 & 2 & 4.4 & 0.212 & $* 1.000$ \\
\hline & Panic disorder & - & - & 1 & 2.2 & 1.011 & $* 1.000$ \\
\hline & $\begin{array}{l}\text { Post-traumatic stress } \\
\text { disorder }\end{array}$ & - & - & 1 & 2.2 & 1.011 & $* 1.000$ \\
\hline & $\begin{array}{l}\text { Generalized anxiety } \\
\text { disorder }\end{array}$ & 4 & 8.9 & 3 & 6.7 & 0.155 & 0.694 \\
\hline \multirow{10}{*}{$\begin{array}{l}\text { Personality } \\
\text { disorders }\end{array}$} & Paranoid & 1 & 2.2 & - & - & \multirow{9}{*}{\multicolumn{2}{|c|}{$\begin{array}{l}\text { The comparison was } \\
\text { made only for the } \\
\text { personality disorders as } \\
\text { a group. }\end{array}$}} \\
\hline & Borderline & 2 & 4.4 & 3 & 7.6 & & \\
\hline & Narcissistic & - & - & 1 & 2.2 & & \\
\hline & Histrionic & 1 & 2.2 & - & - & & \\
\hline & Antisocial & 1 & 2.2 & - & - & & \\
\hline & Obsessive-Compulsive & 4 & 8.9 & 1 & 2.2 & & \\
\hline & Avoidant & - & - & 2 & 4.4 & & \\
\hline & Dependent & 1 & 2.2 & 1 & 2.2 & & \\
\hline & Passive-Aggressive & 2 & 4.4 & - & - & & \\
\hline & $\begin{array}{l}\text { Any personality } \\
\text { disorder }\end{array}$ & 12 & 26.7 & 8 & 17.8 & 1.029 & 0.31 \\
\hline
\end{tabular}

*Fisher's exact test; IBS: irritable bowel syndrome

dimensions) was $224.0 \pm 58.5 \mathrm{~mm}$. The overall severity of the IBS symptoms was not significantly different between the subgroups $(\mathrm{F}=1.784 ; p=0.181)$.

The mean score of the quality of life $( \pm \mathrm{SD})$ was $90.6 \pm 25.2$. The mean score of the quality of life in the three groups of the patients with diarrhea-predominant, constipation-predominant, and alternating IBS was $79.9 \pm 25.2,96.4 \pm 23.0$, and $93.1 \pm 26.1$, respectively, which did not show statistically significant difference $(\mathrm{F}=1.614 ; p=0.212)$.

\section{Defense Mechanisms}

The mean score of projection, acting-out, somatization, autistic fantasy, passive-aggression, and reaction formation in the IBS group was significantly higher than the control group. However, the mean score of humor and anticipation was higher in the control group (table 2).

Also, the use of immature defenses in the IBS group was significantly higher than the control group, whereas the intensity of using mature defenses in the control group was significantly more than the other group.

The severity of immature, mature, and neurotic defen- 
Table 2: Mean $( \pm$ SD) scores of the defense mechanisms in subjects participating in the study

\begin{tabular}{|c|c|c|c|c|c|}
\hline \multirow{2}{*}{$\begin{array}{l}\text { Defensive mechanism } \\
\text { group }\end{array}$} & \multirow{2}{*}{ Defensive mechanism } & \multirow{2}{*}{ IBS group } & \multirow{2}{*}{ Control group } & \multicolumn{2}{|c|}{ comparison statistics ( $t$ test) } \\
\hline & & & & $\mathbf{t}$ & $p$ \\
\hline \multirow[t]{13}{*}{ Immature } & Rationalization & $11.4 \pm 3.5$ & $12.2 \pm 3.8$ & 1.125 & 0.264 \\
\hline & Projection & $7.8 \pm 4.0$ & $5.6 \pm 4.1$ & 2.567 & 0.012 \\
\hline & Denial & $6.2 \pm 2.9$ & $6.3 \pm 3.8$ & 0.031 & 0.975 \\
\hline & Omnipotence & $8.3 \pm 4.4$ & $7.6 \pm 3.7$ & 0.781 & 0.437 \\
\hline & Devaluation & $9.5 \pm 3.9$ & $9.3 \pm 4.1$ & 0.291 & 0.771 \\
\hline & Acting out & $11.4 \pm 4.3$ & $9.5 \pm 4.4$ & 2.057 & 0.043 \\
\hline & Somatization & $12.9 \pm 3.9$ & $10.6 \pm 5.4$ & 2.239 & 0.022 \\
\hline & Autistic fantasy & $9.9 \pm 5.3$ & $6.9 \pm 4.3$ & 2.966 & 0.004 \\
\hline & Splitting & $8.9 \pm 3.6$ & $8.6 \pm 4.9$ & 0.26 & 0.796 \\
\hline & Passive aggression & $9.7 \pm 2.9$ & $7.9 \pm 4.4$ & 2.396 & 0.021 \\
\hline & Displacement & $8.7 \pm 4.7$ & $7.4 \pm 3.7$ & 1.425 & 0.158 \\
\hline & Isolation & $7.7 \pm 3.8$ & $6.9 \pm 4.1$ & 1.011 & 0.315 \\
\hline & Total & $112.5 \pm 22.3$ & $98.9 \pm 25.3$ & 2.709 & 0.008 \\
\hline \multirow[t]{5}{*}{ Mature } & Suppression & $8.7 \pm 4.1$ & $9.5 \pm 4.1$ & 0.86 & 0.387 \\
\hline & Sublimation & $10.2 \pm 4.4$ & $9.8 \pm 4.2$ & 0.491 & 0.625 \\
\hline & Humor & $8.0 \pm 4.5$ & $10.8 \pm 4.6$ & 2.948 & 0.004 \\
\hline & Anticipation & $12.9 \pm 3.6$ & $14.4 \pm 3.1$ & 2.018 & 0.047 \\
\hline & Total & $39.9 \pm 11.1$ & $44.5 \pm 10.8$ & 1.989 & 0.0498 \\
\hline \multirow[t]{5}{*}{ Neurotic } & False altruism & $13.0 \pm 3.9$ & $12.8 \pm 3.6$ & 0.308 & 0.759 \\
\hline & Reaction formation & $10.0 \pm 3.8$ & $7.8 \pm 4.3$ & 2.584 & 0.011 \\
\hline & Intellectualization & $11.0 \pm 4.6$ & $11.3 \pm 4.9$ & 0.29 & 0.773 \\
\hline & Undoing & $11.8 \pm 3.1$ & $11.9 \pm 4.0$ & 0.089 & 0.929 \\
\hline & Total & $45.9 \pm 10.6$ & $43.8 \pm 12.4$ & 0.872 & 0.386 \\
\hline
\end{tabular}

*IBS: irritable bowel syndrome

Table 3: Mean $( \pm$ SD) scores of immature, mature, and neurotic defense mechanisms in subgroups of patients with irritable bowel syndrome

\begin{tabular}{|c|c|c|c|c|c|}
\hline \multirow{2}{*}{ Subscale } & \multirow{2}{*}{ Diarrhea-predominant } & \multirow{2}{*}{ Constipation-predominant } & \multirow{2}{*}{ alternating IBS } & \multicolumn{2}{|c|}{ Statistical tests (ANOVA) } \\
\hline & & & & $\mathbf{F}$ & $p$ \\
\hline Immature & $108.5 \pm 25.1$ & $112.4 \pm 22.9$ & $115.9 \pm 20.3$ & 0.377 & 0.688 \\
\hline Mature & $39.8 \pm 8.6$ & $37.6 \pm 12.8$ & $42.3 \pm 11.1$ & 0.691 & 0.507 \\
\hline Neurotic & $45.6 \pm 12.4$ & $46.3 \pm 10.1$ & $45.8 \pm 10.0$ & 0.013 & 0.987 \\
\hline
\end{tabular}

sive mechanisms did not depend on the existence of any other somatoform disorders $(\mathrm{F}=1.014, p=0.317 ; \mathrm{F}=$ $0.326, p=0.570$; and $\mathrm{F}=0.008, p=0.927$, respectively) and the interaction of IBS and any other somatoform disorder was not statistically significant $(\mathrm{F}=0.416, p=$ $0.521, \mathrm{~F}=3.144, p=0.080$; and $\mathrm{F}=1.648, p=0.203$, respectively).

Similarly, the diagnosis of obsessive-compulsive disorder (which had a different frequency between the two groups) did not show a significant difference in the use of immature, mature, and neurotic defense mechanisms $(\mathrm{F}=1.063, p=0.306 ; \mathrm{F}=2.409, p=0.124$; and $\mathrm{F}=0.144, p=0.725$, respectively) and there was no significant interaction with the main group (IBS or control) $(\mathrm{F}=1.133, p=0.290 ; \mathrm{F}=0.005, \mathrm{p}=0.941 ; \mathrm{F}=0.201$, $p=0.201$, respectively).

The subgroups of IBS did not have a significant statistical difference in this regard (table 3). 
Table 4: Pearson's correlation coefficients between defense mechanisms and the quality of life and severity of irritable bowel syndrome

\begin{tabular}{lccc}
\hline & Immature defenses & Mature defenses & Neurotic defenses \\
\hline Quality of life & 0.226 & 0.125 & 0.087 \\
$(p=0.145)$ & $(p=0.426)$ & 0.137 & 0.095 \\
Severity of disease & 0.212 & $(p=0.369)$ & $(p=0.534)$ \\
\hline
\end{tabular}

Relationship between Types of Defensive Mechanisms with Quality of Life and Severity of IBS

Quality of life (higher scores mean a lower quality of life) had no significant correlation with immature, mature, and neurotic defensive mechanisms. Furthermore, there was no significant correlation between the severity of the disease and the scores of defense mechanisms (table 4).

\section{DISCUSSION}

Psychological and psychobiological factors play a major role in the incidence and the persistence of gastrointestinal functional disorders, including IBS. ${ }^{2,4-7}$ The present study examined the use of defense mechanisms as a group of psychological factors in the patients with IBS.

In general, humans use three types of coping mechanisms to dominate stressful situations. These practices include helping out others, a conscious cognitive way or coping styles, and unconscious defense mechanisms. ${ }^{30}$ Although defense mechanisms are first used to deal with external stressors and internal conflicts, it distorts one's perception of the inner and outer reality, such as denial, suppression, or rejection; thus, this reduces individual anxiety and depression in this way. ${ }^{30,31}$ Some of these mechanisms, such as projection and splitting, are maladaptive, and some, such as denial or suppression, may be adaptive or maladaptive, depending on the severity, flexibility, and context of their occurrence. ${ }^{31}$

In our study, the intensity of the use of projection, acting-out, somatization, autistic fantasy, passive-aggression, and reaction formation was higher in the group with IBS. The major defense mechanisms that were used in the patients with IBS were more common in immature defenses than in the control group. Some of these defense mechanisms, such as somatization and passive-aggression, are obviously associated with anger and anxiety against the patient himself/herself. This finding was also reported in the study of Pokroy and colleagues. ${ }^{18}$

It has been shown that patients with IBS had more escape-avoidance mechanisms in their coping strategies than those in the control group. In the defense mechanisms, turning-against-self defense mechanisms were common. The researchers concluded that the patients with IBS were consciously trying to avoid or escape the problem, rather than effectively coping with them. Some of these tensions are internalized into the gastrointestinal tract. The use of such immature defenses makes it possible for the person to use his anger against himself rather than to resort to a tense agent to deal effectively with it and, according to Ehilevich and Gleser, to use it as a kind of self-punishment. ${ }^{32}$

Some of these mechanisms are different from turningagainst-self mechanisms. For example, based on the classification of Ihilevich and Gleser, acting-out is a kind of defensive mechanism distorting reality towards object. Reaction formation is a kind of reversal defense mechanism, and projection is within a separate category of defense mechanisms. ${ }^{13,19}$ In two other studies that examined the mechanisms used in IBS, there was no significant difference between the two groups of patients and the control group. ${ }^{18,19}$ However sample sizes were obviously limited in the mentioned studies.

Since somatoform disorders have a psychological view of proximity to IBS and as the frequency of obsessive-compulsive disorder in the patients group was higher than the control group, we considered these disorders as the probable interfering factors. But the analysis of variance showed that these disorders did not have an independent role or intervention with IBS in using defense mechanisms. The excessive use of immature mechanisms was also observed in the patients with obsessive-compulsive disorder. ${ }^{33}$

In our study, the use of defense mechanisms neither had any connection with the dominant pattern of the disorder nor showed a significant correlation with the severity of disease or the quality of life. To the best of our knowledge, no other study has addressed this issue. 
In fact, the discrepancy between the three patterns of the disease can be attributed to the limited sample size of the study. Moreover, the incidence of IBS, such as the central amplification of pain ${ }^{5}$ and a decrease of cognitive flexibility, ${ }^{7}$ may be a common factor in all types of IBS. However, it can be thought that reducing inhibitory feedback in the emotional arousal network ${ }^{8}$ and the impairment in the control of the autonomic function of the gastrointestinal tract and the intestinal motor activity ${ }^{9}$ between the different types of the syndrome are different. The relationship between these clinical findings and the psychological mechanisms of the field needs further investigation.

Finally, it should also be noted that in addition to the limited number of the samples, the present study experienced other constraints. The lack of control, among other functional gastrointestinal disorders, does not make it clear whether the difference in the use of defense mechanisms is a common factor among all types of functional gastrointestinal disorders or is only attributed to IBS. The common complication of psychological disorders is also restricting the ability to carefully examine the role of mediator of these disorders. To evaluate this role, we need to review and then compare the patients with no psychiatric disorder with the patients with comorbid psychiatric disorders. Furthermore, although analytical psychotherapy is useful in the treatment of IBS, ${ }^{13}$ the role of these defense mechanisms in the treatment of IBS is unclear.

\section{CONCLUSION}

Based on the findings of the present study, the patients with IBS use more immature defense mechanisms and less mature mechanisms in comparison with healthy people. These findings may play significant roles in psychodynamic and supportive psychotherapy of the patients with IBS. However, the importance of using these mechanisms and their exact role in the formation of disruptions to supplementary studies are essential.

\section{ETHICAL APPROVAL}

There is nothing to be declared.

\section{CONFLICT OF INTEREST}

The authors declare no conflict of interest related to this work.

\section{REFERENCES}

1. Bose M, Farthing MJG. Irritable bowel syndrome: new horizons in pathophysiology and treatment. Br J Surg 2001;88:1425-6. doi:10.1046/j.0007-1323.2001.01870.x.

2. Liu J, Hou X. A review of the irritable bowel syndrome investigation on epidemiology, pathogenesis and pathophysiology in China. J Gastroenterol Hepathol 2011;26 Suppl 3:88-93. doi:10.1111/j.1440-1746.2011.06641.x.

3. El-Salhy M, Hatlebakk JG, Gilja OH, Hausken T. Irritable bowel syndrome: recent development in diagnosis, pathophysiology, and treatment. Expert Rev Gastroenterol Hepatol 2014;8:435-43. doi:10.1586/17474124.2014.888952.

4. Drosmann DA, Camilleri M, Mayer EA, Whitehead WE. AGA technical review on irritable bowel syndrome. Gastroenterology 2002;123:2108-31. doi:10.1053/gast.2002.37095.

5. Gupta A, Kilpatrick L, Labus J, Tillisch K, Braun A, Hong JY, et al. Early adverse life events and resting state neural networks in patients with chronic abdominal pain: evidence for sex differences. Psychosom Med 2014;76:40412. doi:10.1097/PSY.0000000000000089.

6. Park SH, Videlock EJ, Shih W, Presson AP, Mayer EA, Chang L. Adverse childhood experiences are associated with irritable bowel syndrome and gastrointestinal symptom severity. Neurogastroenterol Motil 2016;28:1252-60. doi:10.1111/nmo.12826.

7. Aizawa E, Sato Y, Kochiyama T, Saito N, Izumiyama M, Morishita J, et al. Altered cognitive function of prefrontal cortex during error feedback in patients with irritable bowel syndrome, based on fMRI and dynamic causal modeling. Gastroenterology 2012;143:1188-98. doi: 10.1053/j.gastro.2012.07.104.

8. Hall GB, Kamath MV, Collins S, Ganguli S, Spaziani R, Miranda KL, et al. Heightened central affective response to visceral sensations of pain and discomfort in IBS. Neurogastroenterol Motil 2010;22:276-80. doi: 10.1111/j.1365-2982.2009.01436.x.

9. Tillisch K, Mayer EA, Labus JS. Quantitative metaanalysis identifies brain regions activated during rectal distension in irritable bowel syndrome. Gastroenterology 2011;140:91-100. doi:10.1053/j.gastro.2010.07.053.

10. Padhy SK, Mishra S, Sarkar S, Bang LG, Panigrahi M. Comparison of psychiatric morbidity in patients with irritable bowel syndrome and non-ulcer dyspepsia. Ind Psychiatry J 2016;25:29-34. doi:10.4103/0972-6748.196038.

11. Holtmann GJ, Ford AC, Talley NJ. Pathophysiology of irritable bowel syndrome. Lancet Gastroenterol Hepatol 2016;1:133-46. doi:10.1016/S2468-1253(16)30023-1.

12. Ford AC, Quigley EM, Lacy BE, Lembo AJ, Saito YA, Schiller LR, et al. Effect of antidepressants and psychological therapies, including hypnotherapy, in irritable bowel syndrome: systematic review and meta-analysis. Am J Gastroenterol 2014;109:1350-65. doi:10.1038/ajg.2014.148.

13. Ballou S, Keefer L. Psychological Interventions for Irritable Bowel Syndrome and Inflammatory Bowel Diseases. Clin Transl Gastroenterol 2017;8:e214. doi:10.1038/ctg.2016.69. 
14. Evans PR, Bennett EJ, Bak YT, Tennent CC, Kellow JE. Jejeunal sensorimotor dysfunction in irritable bowel syndrome: clinical and psychosocial features. Gastroenterol 1996;110:393-404. doi:10.1053/gast.1996.v110. pm8566585.

15. Chokraborty U, Gupta SD, Todi D. A short study on relationships between anger and defense style in functional gastrointestinal disorder. Ind $J$ Health Wellbeing 2014;5:27-33.

16. American Psychiatric Association. Diagnostic and Statistical Manual of Mental Disorders, Fifth Edition. Washington, Am Psychiatr Assoc 2013.

17. Meissner W. Theories of personality and psychopathology. In: Sadock BJ, Sadock VA, Ruiz P (eds.) Kaplan and Sadock's Comprehensive Textbook of Psychiatry. 10th edition. Philadelphia; Lippincott Williams and Wilkins 2017.

18. Pokroy R, Mayer A, Stuart AD, Pretorius HG. Coping styles and defense mechanisms utilized by patients suffering from irritable bowel syndrome. Health SA Gesondheid 1999;4:28-34. doi:10.4102/hsag.v4i1.8.

19. Zoccali R, Muscatello MR, Bruno A, Barillà G, Campolo $\mathrm{D}$, Meduri M, et al. Anger and ego-defense mechanisms in non-psychiatric patients with irritable bowel syndrome. Dig Liver Dis 2006;38:195-200. doi:10.1016/j. dld.2005.10.028.

20. Longstreth GF, Thompson WG, Chey WD, Houghton LA, Mearin F, Spiller RC. Functional bowel disorders. Gastroenterololy 2006;130:1480-91. doi:10.1053/j.gastro.2005.11.061

21. First MB, Spitzer RL, Gibbon M, Williams JBW. Structured Clinical Interview for DSM-IV-TR Axis I Disorders, Research Version, Patient Edition. (SCID-I/P) New York: Biometrics Research, New York State Psychiatric Institute, 2002.

22. Andrews G, Singh M, Bond M. The Defense Style Questionnaire. J Nerv Ment Dis 1993;181:246-56.

23. Chabrol H, Callahan S, Pirlot G, Sztulman H, Peresson $\mathrm{G}$, Teissedre F, et al. [Validity study of the DSQ-40 (Defense Style Questionnaire, 40 items version)]. Encephale 2005;31:385-6.

24. Behzadipour S, Rezaei Kargar F, Sepah Mansour M, Nooh S. Personality characteristics and defense mechanisms in obese persons compared with normal-weight persons. Thought Behav Clin Psychol 2011;6:25-34.

25. Francis C, Morris J, Whorwell P. The irritable bowel severity scoring system: a simple method of monitoring irritable bowel syndrome and its progress. Aliment Pharmacol Ther 1997;11:395-402. doi:10.1046/j.13652036.1997.142318000.x.

26. Duncan GH, Bushnell MC, Lavigne GJ. Comparison of verbal and visual analogue scales for measuring the intensity and unpleasantness of experimental pain. Pain 1989;37:295-303. doi:10.1016/0304-3959(89)90194-2.

27. Patrick DL, Drossman DA, Frederic IO, DiCesare J, Puder KL. Quality of life in persons with irritable bowel syndrome: development and validation of a new questionnaire. Dig Dis Sci 1998;43:400-11. doi: 10.1023/A:1018831127942.

28. Jafari P, Asadollahi Z, Moini M, Mirzaie MS. Health related quality of life in Iranian patients with Irritable Bowel Syndrome: Reliability and validity of the Persian version of the IBS-QOL. Iran Red Crescent Med J 2013;15:723-8. doi:10.5812/ircmj.4605.

29. Masaeli N, Kheirabadi GR, Afshar H, Daghaghzadeh H, Maracy MR, Assadolahi F, et al. Validity, reliability, and factor analysis of Persian version of quality of life questionnaire for irritable bowel syndrome (IBS-QOL-34). $J$ Res Med Sci 2013;18:492-6.

30. Vaillant GE, Vaillant CO. Normality and mental health. In: Sadock BJ, Sadock VA, Ruiz P (eds.) Kaplan and Sadock's Comprehensive Textbook of Psychiatry. 9th edition. Philadelphia; Lippincott Williams and Wilkins 2009.

31. Cramer P. Coping and defense mechanisms: what's the difference? J Pers 2002;66:919-46. doi:10.1111/14676494.00037

32. Ihilevich D, Gleser GC. Defense mechanisms, their classification, correlations \& measurement with the Defense Mechanisms InventoryOwosso, MI:DMI Associates; 1986.

33. Shabanpour R, Zahiroddin AR, Janbozorgi M, Ghaeli P. Assessment of defense styles and mechanisms in Iranian patients suffering from obsessive compulsive and panic disorders versus normal controls using Persian Version of Defense Style Questionnaire-40. Iran J Psychiatry 2012;7:31-5. 